\title{
Study of thermally coupled distillation systems for energy-efficient distillation
}

\author{
NEHA SAXENA ${ }^{1}$, NILESH MALI ${ }^{2, *}$ and SATCHIDANAND SATPUTE ${ }^{3}$ \\ ${ }^{1}$ Department of Chemical Engineering, Bharati Vidyapeeth Deemed University College of Engineering, \\ Pune 411046, India \\ ${ }^{2}$ Chemical Engineering and Process Development Division, CSIR-National Chemical Laboratory, Dr. Homi \\ Bhabha Road, Pune 411008, India \\ ${ }^{3}$ Department of Chemical Engineering, Vishwakarma Institute of Technology, Bibwewadi, Pune 411037, India \\ e-mail: na.mali@ncl.res.in
}

MS received 19 November 2015; revised 27 June 2016; accepted 6 July 2016

\begin{abstract}
Distillation is one of the most widely used separation unit operations in process industries, although it is quite energy intensive. In many cases, the enormous energy requirements for distillation make it economically infeasible to carry out the separation. Thermally coupled distillation system (TCDS) is an advanced distillation method that provides significant energy savings of about $30 \%$ as compared with conventional distillation column sequences. The most well-known TCDS sequence, the Petlyuk configuration, has some operational challenges due to bidirectional vapour flow, which makes its implementation difficult in two-column mode. To overcome these limitations, a number of unidirectional vapour flow configurations have been proposed in the literature. The work on simulation analysis for such configurations is limited. In this paper, simulation models for two such configurations are developed, analyzed and compared with the Petlyuk and conventional distillation column sequences for separation of equimolar mixture of benzene-toluene-ethylbenzene.
\end{abstract}

Keywords. Distillation; energy efficient; thermally coupled; Petlyuk; simulation.

\section{Introduction}

Distillation is a process in which a liquid and/or vapour mixture of two or more substances is separated into its component fractions of desired purity by the application and removal of heat. This separation is based on the difference in the relative volatility of the components in the feed mixture. It is one of the well-known and most widely used separation methods. Distillation separations are performed for about $95 \%$ of all fluid separations in the chemical industry and require an enormous amount of energy. Distillation units consume about $3 \%$ of the total energy consumption of the world [1].

Different configurations to carry out distillation separations have been developed in order to minimize the energy consumption involved in this unit operation. Any reduction in energy consumption not only provides economical benefits but also helps reduce emissions associated with the use of the fossil fuels [2]. Thermally coupled distillation system (TCDS) is one of such configurations. TCDS was first proposed by Wright [3] as a divided wall column and later theoretical studies were performed by Petlyuk et al [4]. The fully thermally coupled distillation sequence (FTCDS) is also

*For correspondence referred to as a Petlyuk column. The side rectifier and side stripper are well-known applications of partially thermally coupled distillation system. Fidkowski and Krolikwoski [5] analysed the energy consumption in Petlyuk, conventional direct and indirect sequences as well as the partially thermally coupled sequences with side columns and proved that the energy consumption is the lowest in the Petlyuk column.

In conventional distillation sequences, as shown in figures 1 and 2, remixing of the intermediate component occurs in the first column. The concentration of intermediate component reaches a certain maximum value near the feed stage and then decreases towards the bottom of the column. This remixing of the intermediate component within the column leads to additional energy requirement to re-purify the binary mixture in the second column. On the other hand, in TCDS sequences, as shown in figure 3, the presence of a prefractionator (column 1) significantly reduces the remixing of intermediate component. Hence, the energy consumption of TCDS is significantly lower as compared with that in conventional distillation column sequences. The intermediate component is drawn as the side product from the main column at the stage where its concentration is the highest. The reported energy saving of TCDS is about $30 \%$ as compared to that for conventional direct and indirect sequences for ternary separations [6]. 


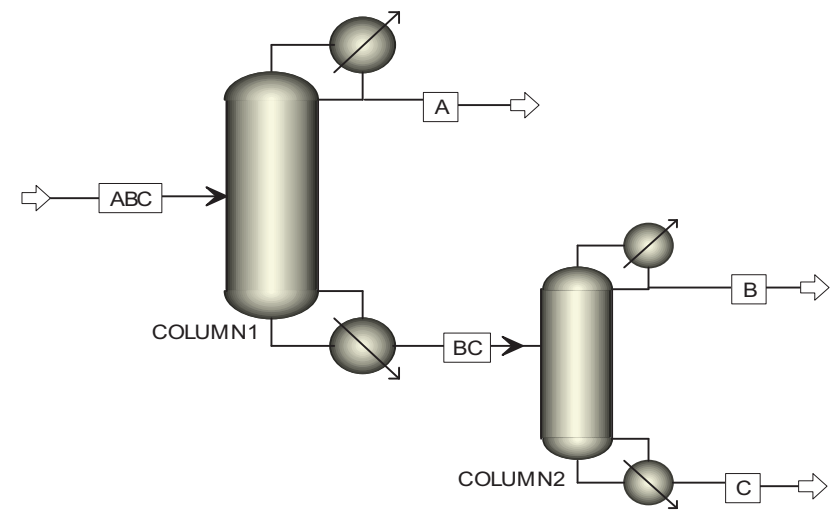

Figure 1. Direct distillation sequence for ternary mixtures.

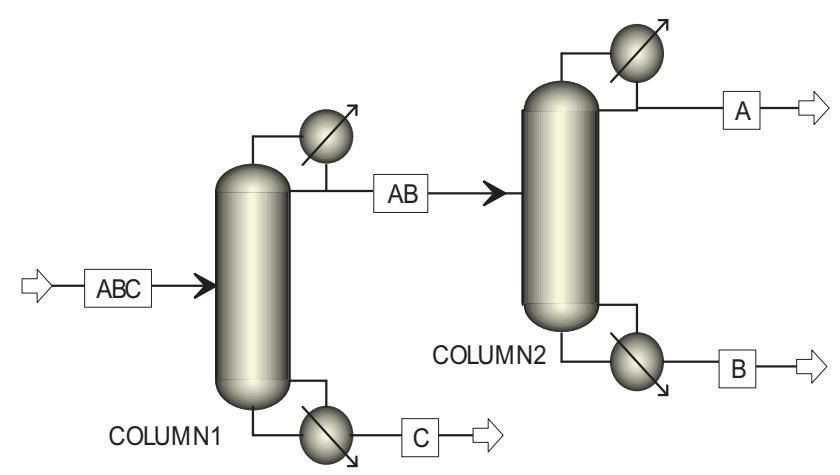

Figure 2. Indirect distillation sequence for ternary mixtures.

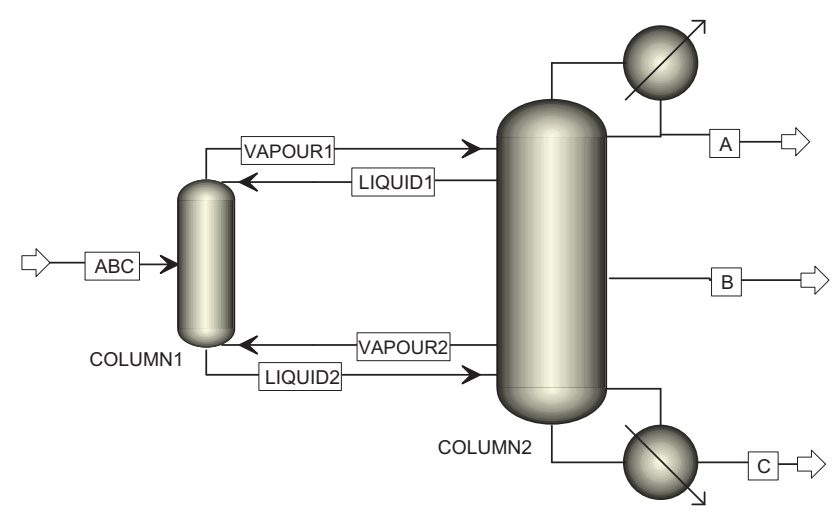

Figure 3. Petlyuk configuration for ternary mixtures.

\section{Operational challenges in the Petlyuk column}

Despite being energy efficient than the conventional distillation sequences and the sequences with side stripper and side rectifier, there is hardly any practical implementation of the Petlyuk configuration in two-column mode. The divided wall column (DWC) as shown in figure 4 is thermodynamically equivalent to the Petlyuk column and is

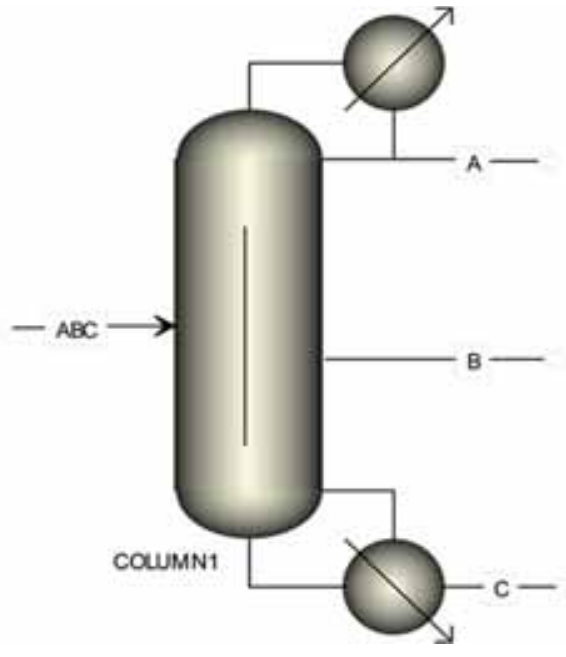

Figure 4. Dividing wall column.

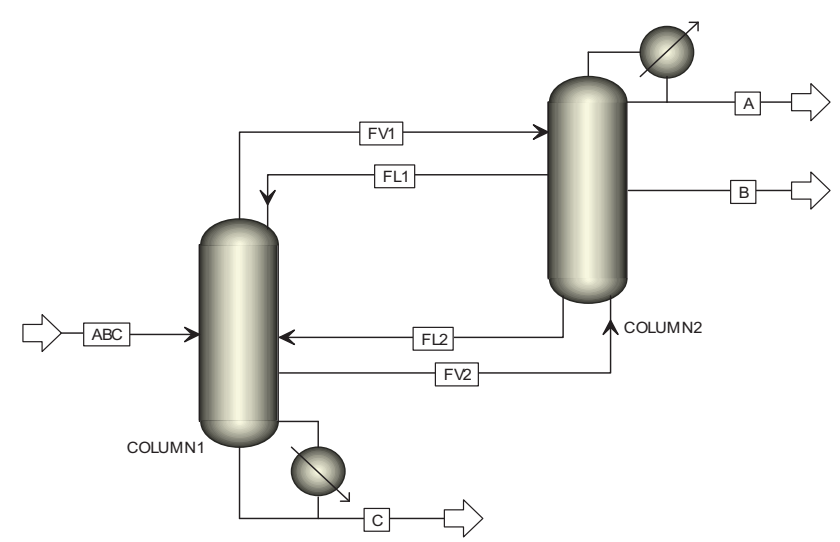

Figure 5. Unidirectional vapour flow TCDS configuration 1.

implemented within a single column. A conventional (direct or indirect) distillation sequence can be converted into a more-energy-efficient FTCDS, either in single column as DWC (figure 4) or in a two-column configuration (figure 3). The DWC has been implemented in many process industries successfully for various separation tasks [7]. The implementation of Petlyuk column in two-column mode has found no application in industries. This is due to some operational challenges involved in this configuration, related to vapour flows.

In the Petlyuk column (figure 3), one vapour stream flows from the top of the prefractionator to the upper section of main column, while another vapour stream is from the lower section of main column to the bottom of the prefractionator. Thus, the vapour flows in two directions between the two columns. For the proper vapour flow between the two columns, the pressure in the upper part of the prefractionator should be kept higher than that of the upper part of the main column; on the other hand, the pressure in the lower part of the main column should be 


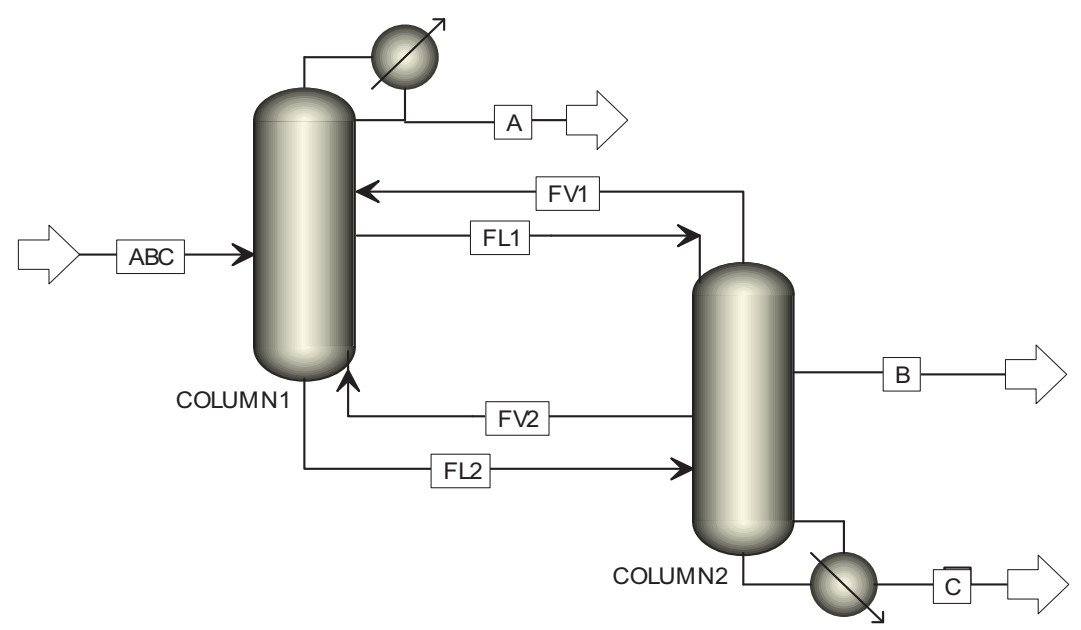

Figure 6. Unidirectional vapour flow TCDS configuration 2.

Table 1. Basis for the simulation analysis.

\begin{tabular}{|c|c|c|c|}
\hline Component & Feed composition & Product specification & Other conditions \\
\hline Benzene & 0.33 & 0.995 & Column pressure $=1.75 \mathrm{bar}$ \\
\hline Toluene & 0.33 & 0.96 & Total condenser \\
\hline Ethylbenzene & 0.34 & 0.96 & Peng-Robinson model \\
\hline
\end{tabular}

kept higher than that of the lower part of the prefractionator [8]. It implies that the pressure in the upper and lower parts of the columns should be maintained at different values. It is very difficult to achieve such a pressure profile in both columns simultaneously during operation, and hence the use of such configuration becomes almost impractical.

Dividing-wall column technology was developed and implemented by a few companies like BASF, UOP, Montz, etc. The know-how for actual implementation is not

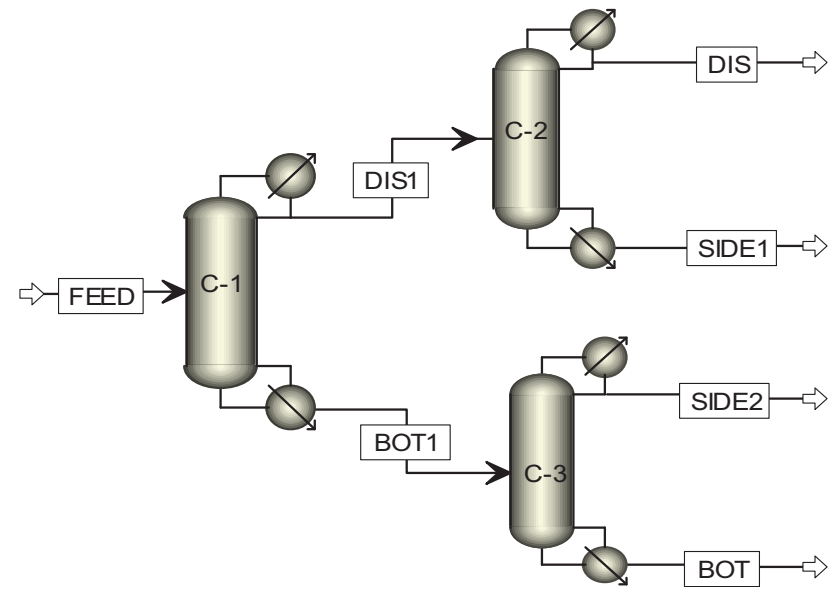

Figure 7. Three-column shortcut simulation model. available in the open literature and is proprietary information of those companies. Hence, implementation of dividing-wall-column is not that straight forward unless companies with this know-how are approached.

Also, dividing-wall-column is not feasible for all kinds of separations. For a component system that needs two columns at different pressures in conventional distillation sequence, dividing-wall-column is not feasible as it operates at a single pressure.

For existing distillation column sequences, it may be possible to convert them to thermally coupled sequence with some additional piping and some changes in column internals. Hence, the authors believe that two-column implementation of thermally coupled sequence still carries its importance although single-column option is feasible for some cases.

\section{Unidirectional vapour flow configurations of TCDS}

To overcome the operational difficulties of Petlyuk configuration, some new configurations have been reported in the literature. The vapour flows in these reported configurations are easier to manage, making them more operable than the Petlyuk column. 
Table 2. Key component recoveries of all columns.

\begin{tabular}{lcc}
\hline Column & Light key component recovery & Heavy key component recovery \\
\hline C-1 & Benzene $(0.99)$ & Ethylbenzene $(0.01)$ \\
C-2 & Benzene $(0.997)$ & Toluene $(0.0148)$ \\
C-3 & Toluene $(0.938)$ & Ethylbenzene $(0.0154)$ \\
\hline
\end{tabular}

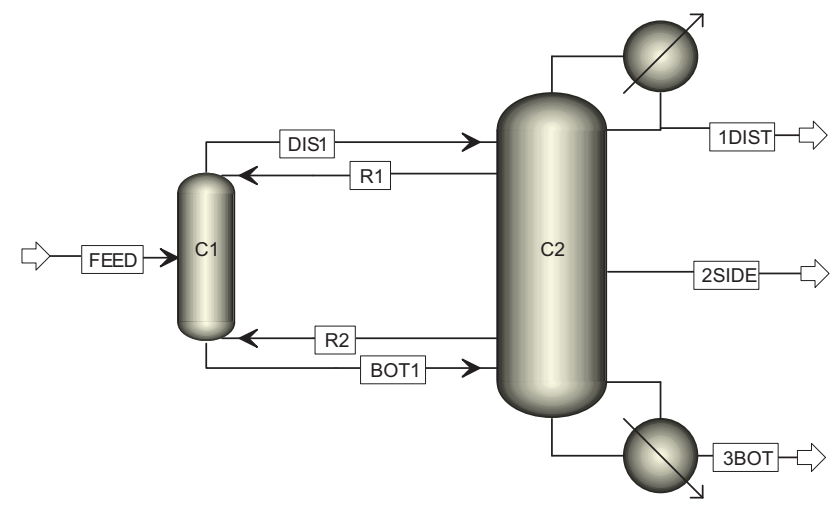

Figure 8. Aspen simulation model for the Petlyuk configuration.

The configurations 1 (figure 5) and 2 (figure 6) were proposed by Agrawal and Fidkowski [8]. These configurations were found by the rearrangement of the condenser and reboiler in the Petlyuk configuration. In configuration 1 (figure 5), the vapour streams, FV1 from the top of the first column and FV2 from an intermediate stage of the first column, enter the second column. The heavy component (C) is removed from the bottom of the first column and the light (A) and intermediate (B) are drawn from the top and side stage of the second column, respectively.

In configuration 2, the vapour streams FV1 and FV2 emerge from the second column and enter the first column, as shown in figure 6. The light component $(\mathrm{A})$ is removed from the top of the first column and the heavy $(\mathrm{C})$ and intermediate (B) components are, respectively, drawn from the bottom stage and an intermediate side stage of the second column.

Since, the vapour flow in these configurations is in one direction, there will not be any operational difficulty in adjusting the pressure profile of both the columns. The pressure of column supplying the vapour should be kept higher than in the other column. Since these configurations require only one reboiler and one condenser, they may provide energy savings comparable to that of Petlyuk, at given feed conditions.

The simulation analysis to quantify energy saving potential for such new configurations is limited in the literature. In this work, two of the unidirectional vapour flow configurations have been discussed. The performance of these configurations was analysed for equimolar feed composition through simulation analysis and is discussed in section 4. The simulation strategy can also be extended for various feed compositions to quantify energy saving potential of thermally coupled configuration. This analysis can also be used as a basis to retrofit present conventional distillation sequence to suitable thermally coupled configuration to minimize energy consumption and designing the additional piping network between the existing columns.

\section{Simulation analysis}

Simulation models were developed and analyzed in detail for Petlyuk system; unidirectional vapour flow thermally coupled configurations 1 and 2. These configurations were optimized in terms of energy consumption using rigorous simulations in the process simulator Aspen Plus. These results were compared with that of the conventional distillation sequences for the same separation task.

The basis was taken from the work of Premkumar and Rangaiah [2]. The saturated liquid feed mixture comprising benzene/toluene/ethylbenzene in equimolar composition was fed to the column at $100 \mathrm{kmol} / \mathrm{h}$ and 1.75 bar pressure. Other specifications for this simulation analysis which are taken as basis are listed in table 1.

All the configurations in the present study were compared based on the optimized performance, in terms of energy consumption as well as minimum number of stages for the composition constraints mentioned in table 1 . This is because the comparison of different thermally coupled distillation configurations based on equal number of stages may not be a fair comparison, as both the capital investment as well as operating cost need to be considered while choosing appropriate configuration for a given separation task.

\subsection{Petlyuk column}

4.1a Shortcut simulation: An approximate design was first obtained by developing three-column shortcut simulation model, as shown in figure 7 (based on Winn-UnderwoodGilliland method), as proposed by Premkumar and Rangaiah [2]. In this model, column $\mathrm{C} 1$ represents the prefractionator and columns $\mathrm{C} 2$ and $\mathrm{C} 3$ together represent the 

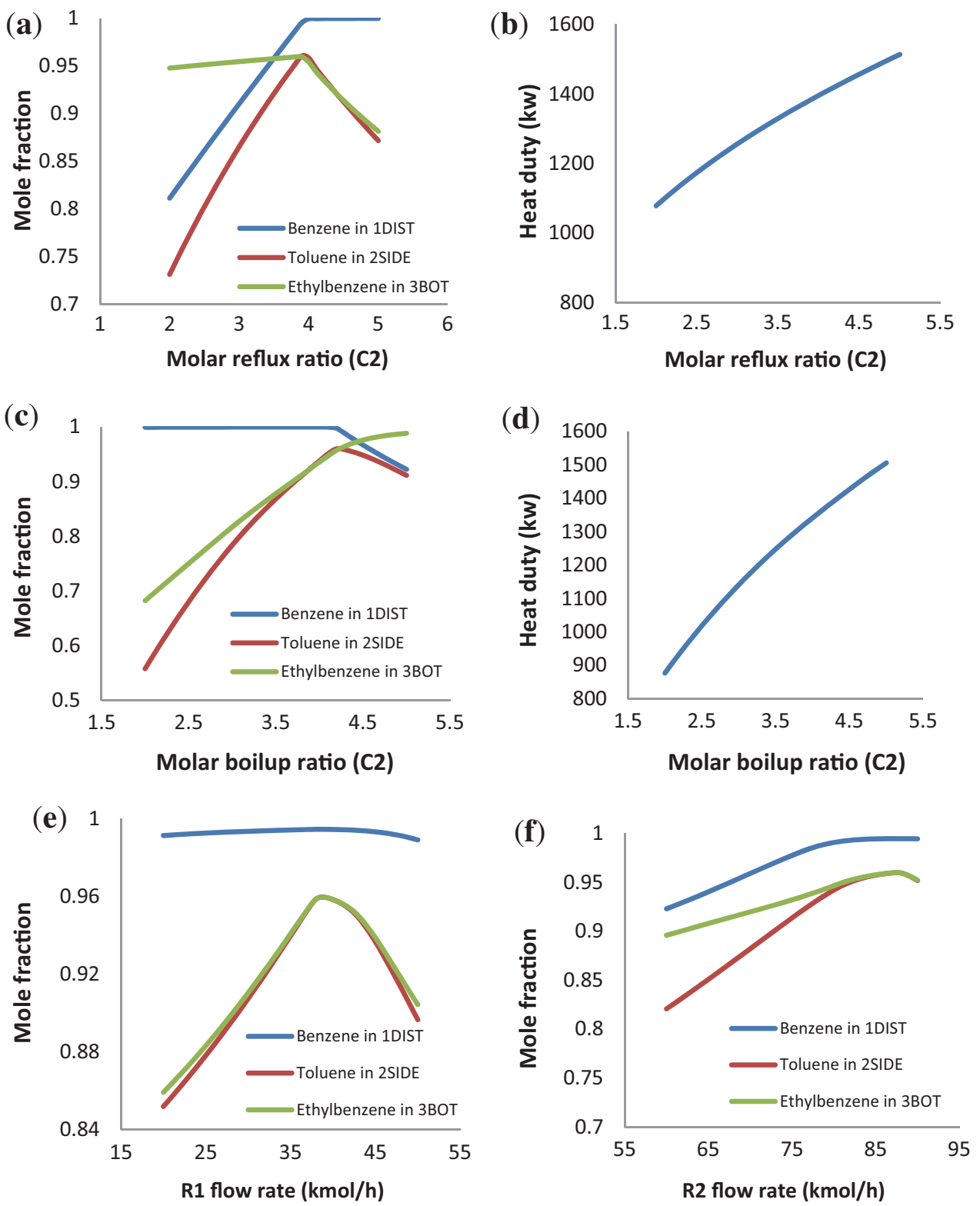

Figure 9. Sensitivity analysis results for the Petlyuk configuration.

main column of the Petlyuk configuration. $\mathrm{C} 1$ has a partial condenser, and $\mathrm{C} 2$ and $\mathrm{C} 3$ have a total condenser.

The light component is obtained from the stream DIS and the heavy component is obtained from the stream BOT. The intermediate component is obtained from two streams SIDE1 and SIDE2. Since these streams together represent the side flow, they must have the same molar composition. The model was simulated by specifying the key component recoveries of columns $\mathrm{C}-1, \mathrm{C}-2$ and $\mathrm{C}-3$ as per the purity requirements. The light key component recovery is the ratio of moles of light key in distillate to the moles of light key in feed. Similarly, the heavy key component recovery is the ratio of moles of heavy key in distillate to that in the feed. Shortcut simulation provides the initial estimates required for the rigorous simulation. The specified key component recoveries for this configuration are shown in table 2 .

4.1b Rigorous simulation: For rigorous simulation, the RadFrac model of Aspen was used. The Aspen simulation model for the Petlyuk configuration, comprised of two RadFrac models, is shown in figure 8. A converged solution was first reached by using the estimates obtained from shortcut simulation. Initial guesses for the recycle streams R1 and R2 must be given to avoid convergence problems. The energy optimization was done by observing the effect of different parameters on the product compositions and heat duty, using sensitivity analysis. The graphs of sensitivity are shown in figure 9. 
Table 3. Optimum values of different parameters (Petlyuk column).

\begin{tabular}{lc}
\hline Parameter & Optimized value \\
\hline Molar reflux ratio (C2) & 3.89 \\
Molar boilup ratio (C2) & 4.23 \\
R1 flow rate $(\mathrm{kmol} / \mathrm{h})$ & 39 \\
R2 flow rate $(\mathrm{kmol} / \mathrm{h})$ & 87 \\
Distillate flow rate $(\mathrm{C} 2)$ & 33.09 \\
Side flow rate $(\mathrm{C} 2)$ & 32.76 \\
Bottom flow rate $(\mathrm{C} 2)$ & 34.14 \\
Number of stages $(\mathrm{C} 1)$ & 25 \\
Number of stages $(\mathrm{C} 2)$ & 61
\end{tabular}

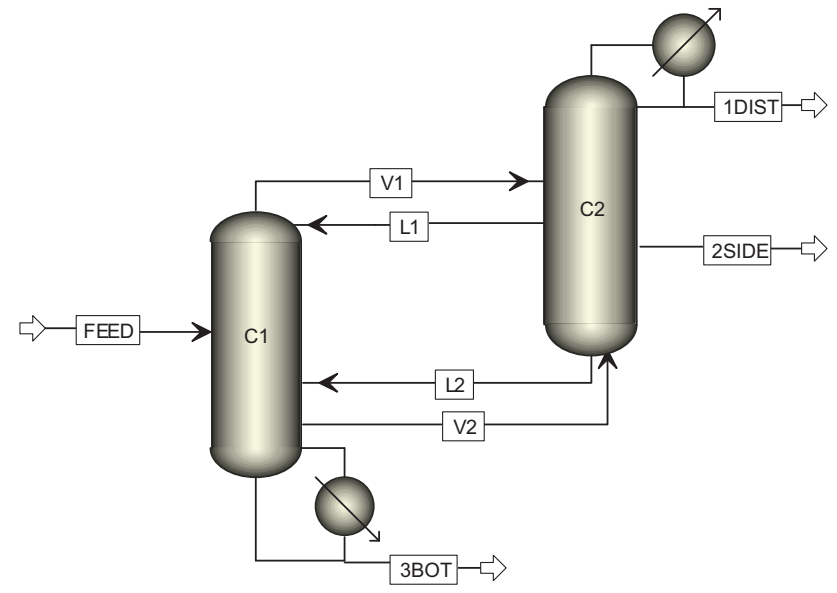

Figure 10. Aspen simulation model for unidirectional vapour flow configuration 1 .

From figure $9 \mathrm{a}$ and $\mathrm{b}$, it is observed that the compositions pass through a maxima as the reflux ratio increases and the reboiler heat duty is directly proportional to the reflux ratio. The optimum value of reflux ratio selected is 3.4 , as at this point all desired compositions have been reached. Similarly, in case of sensitivity with molar boilup ratio shown in figure $9 \mathrm{c}$ and $\mathrm{d}$, as the reboiler heat duty has direct relationship with the boilup ratio, the optimum boilup ratio is the minimum boilup ratio for which all desired compositions are reached. The optimum molar boilup ratio is 4.2. The optimum solution represents values in graphs at which the reboiler duty is the lowest, provided all the constraints of purity have met. The number of stages, in both the columns, was first kept at a certain number above the minimum number of stages provided by the shortcut simulation. The desired product composition was then reached by adjusting the number of stages and other operating parameters. The stages in both the columns were then systematically minimized by analysing the composition profile. All optimized parameters for the Petlyuk configuration are shown in table 3.
An analytical method was proposed by Fidkowski and Krolikowski [9] for the optimization of the Petlyuk system. The authors calculated the minimum vapour flow required to carry out the desired separation. The following equation for the minimum vapour flow calculation was derived:

$$
V_{\min }=\max \left[\frac{\alpha_{A} \mathrm{~A}}{\alpha_{A}-1}, \frac{\alpha_{A} \mathrm{~A}}{\alpha_{A}-\phi 2}+\frac{\alpha_{B} \mathrm{~B}}{\alpha_{B}-\phi 2}\right]
$$

where $\phi$ are the roots of Underwood's equation

$$
\left[\frac{\alpha_{A} \mathrm{~A}}{\alpha_{A}-\phi}, \frac{\alpha_{B} \mathrm{~B}}{\alpha_{B}-\phi}+\frac{\alpha_{C} \mathrm{C}}{\alpha_{C}-\phi}\right]=0 .
$$

$\alpha$ represent the relative volatility, and $\mathrm{A}, \mathrm{B}$ and $\mathrm{C}$ are the flow rates of component $(\mathrm{kmol} / \mathrm{h}) \mathrm{A}, \mathrm{B}$ and $\mathrm{C}$, respectively.

The first and second terms of Eq. (1) (in the brackets) are calculated. The minimum vapour flow is the one with the larger value.

The value for the minimum vapour flow calculated from the above equation for this case was found to be 145.06 $\mathrm{kmol} / \mathrm{h}$. The vapour flow rate obtained by the rigorous simulation was $144.32 \mathrm{kmol} / \mathrm{h}$, which ensures that the solution obtained is optimum.

\subsection{Unidirectional vapour flow configuration 1}

In this case, rigorous simulations were performed directly, as no shortcut-simulation model is available for such configurations in the literature. The Aspen simulation model developed for configuration 1 is shown in figure 10 . The effect of various parameters on the product compositions and the reboiler heat duty was analysed to optimize the configuration, using sensitivity analysis. The graphs for the same are shown in figure 11. The vapour flow from the reboiler to the bottom of column C2 was found to be $139.85 \mathrm{kmol} / \mathrm{h}$.

In this case, the optimization was done in a similar way as that for the Petlyuk configuration. The optimum values of all parameters, like reflux ratio, boilup ratio and flow rates of $L 1$ and $V 2$, are selected from figure $11 \mathrm{a}-\mathrm{f}$, as the point at which the reboiler duty is the minimum and all desired purities have been reached. The simulation was started with the number of stages in both the columns with some number above than that in the Petlyuk configuration.

The number of stages along with other operating parameters was then varied to reach the desired product compositions. The stages in both the columns were further minimized systematically by analysing the composition profile while optimizing other operating parameters. The optimized parameters are given in table 4 .

\subsection{Unidirectional vapour flow configuration 2}

In this case too, rigorous simulations were performed directly as no shortcut-simulation model is available. The simulation model developed for this configuration is shown 

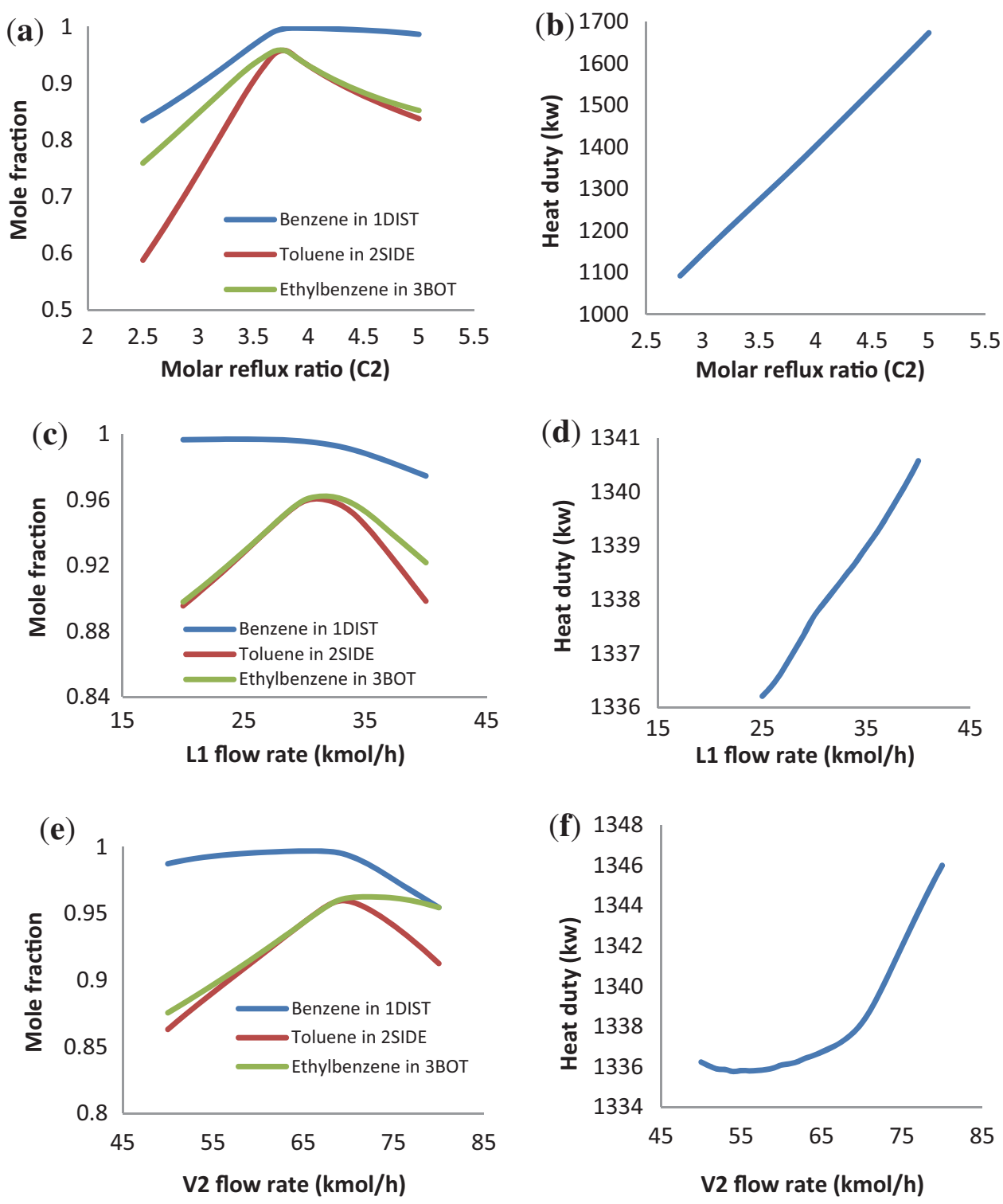

Figure 11. Sensitivity analysis results for unidirectional vapour flow configuration 1.

Table 4. Optimum values of different parameters (configuration 1).

\begin{tabular}{lc}
\hline Parameter & Optimized value \\
\hline Molar reflux ratio $(\mathrm{C} 2)$ & 3.75 \\
Molar boilup ratio $(\mathrm{C} 1)$ & 4.09 \\
L1 flow rate $(\mathrm{kmol} / \mathrm{h})$ & 30.14 \\
$V 2$ flow rate $(\mathrm{kmol} / \mathrm{h})$ & 69.03 \\
Distillate flow rate $(\mathrm{C} 2)$ & 32.96 \\
Side flow rate $(\mathrm{C} 2)$ & 32.82 \\
Bottom flow rate $(\mathrm{C} 1)$ & 34.22 \\
Number of stages $(\mathrm{C} 1)$ & 47 \\
Number of stages $(\mathrm{C} 2)$ & 46 \\
\hline
\end{tabular}

in figure 12. This configuration was also optimized in a similar manner as the above two configurations. The reflux ratio for column $\mathrm{C} 1$, the flow rates $L 1, V 2$ and 2 SIDE and boilup ratio for column $\mathrm{C} 2$ were optimized. The sensitivity analysis graphs are shown in figure 13. The vapour flow from the reboiler to the bottom of the column $\mathrm{C} 2$ was found to be $147.94 \mathrm{kmol} / \mathrm{h}$.

The optimization methodology is similar as that in the above two configurations. From figure 13a-f, all optimum parameters are selected such that the heat duty is the lowest, provided the product compositions have reached. The number of stages in this configuration was minimized in a similar way as that of configuration 1 . The optimum values are given in table 5 . 


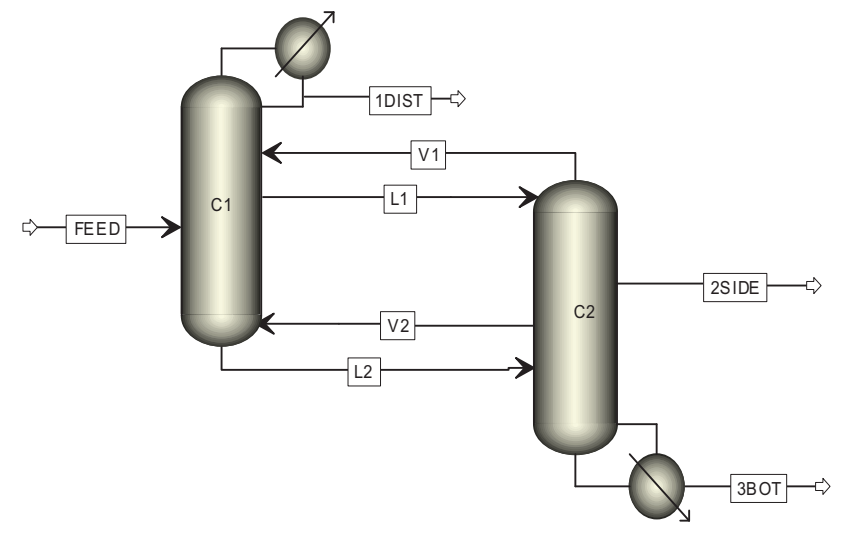

Figure 12. Aspen simulation model for more operable configuration 2 .

\subsection{Conventional distillation sequence}

The direct and indirect configurations, for the BTE separation were also simulated and optimized using the optimization block of Aspen Plus. The objective function was to minimize the sum of reboiler duties of both the columns, with the desired purities as constraints. The optimum values achieved are as shown in table 6.

The number of stages in the conventional sequences was decided by shortcut simulation in Aspen Plus, based on the Winn-Underwood-Gilliland method. The minimum number of stages was firstly calculated using the DSTWU model. The actual number of trays was taken as 1.5 times the minimum number of stages obtained from the DSTWU model.
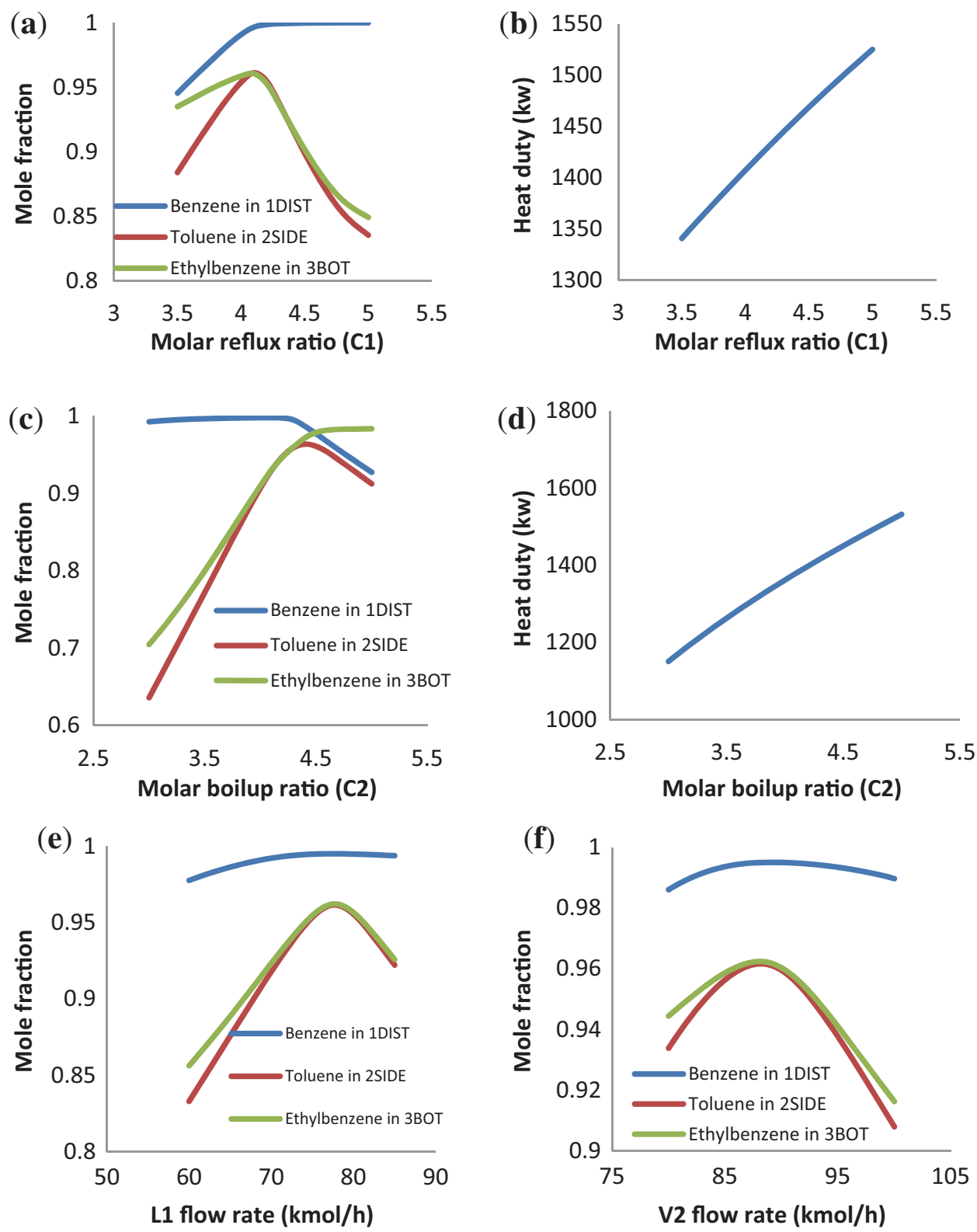

Figure 13. Sensitivity analysis results for unidirectional vapour flow configuration 2 . 


\section{Results and discussion}

The results of simulation summarized in table 7 show that the conventional (direct and indirect) sequences require the highest reboiler duty for the given separation. The energy savings for TCDS are calculated with respect to the indirect configuration, as it is more energy efficient than the direct configuration for the given feed conditions.

$$
\begin{aligned}
& \% \text { Energy savings } \\
& =\frac{\text { reboiler duty (indirect) }- \text { reboiler duty (configuration) }}{\text { reboiler duty (indirect) }}
\end{aligned}
$$

The Petlyuk column provides an energy savings of about $33 \%$, but requires large number of stages $(25+61)$.

Table 5. Optimum values of different parameters (configuration 2).

\begin{tabular}{lc}
\hline Parameter & Optimized value \\
\hline Molar reflux ratio (C1) & 4.06 \\
Molar boilup ratio (C2) & 4.3 \\
$L 1$ flow rate $(\mathrm{kmol} / \mathrm{h})$ & 79 \\
$V 2$ flow rate $(\mathrm{kmol} / \mathrm{h})$ & 90 \\
Distillate flow rate $(\mathrm{C} 1)$ & 32.79 \\
Side flow rate $(\mathrm{C} 2)$ & 32.8 \\
Bottom flow rate $(\mathrm{C} 2)$ & 34.41 \\
Number of stages $(\mathrm{C} 1)$ & 28 \\
Number of stages $(\mathrm{C} 2)$ & 40 \\
\hline
\end{tabular}

Configuration 1 shows the maximum energy saving, about $35 \%$, but the number of stages in this case is the highest $(47+46)$. As far as configuration 2 is concerned, the number of stages is the minimum $(28+40)$ and energy savings of about $31 \%$ is observed.

\section{Conclusion}

In the present work, two unidirectional vapour flow fully thermally coupled configurations have been analysed in detail for the separation of equimolar feed mixture. Simulation models were developed in the process simulator Aspen Plus. Models were optimized for the given feed conditions to minimize the reboiler duty and number of equilibrium stages.

The results from simulation show that for the equimolar feed composition, the maximum energy savings are in the case of configuration 1 , followed by Petlyuk and configuration 2. But the number of stages is the highest in configuration 1, followed by Petlyuk. The number of stages is significantly lower in configuration 2 as compared to Petlyuk and configuration 1. Configuration 2 is the optimum choice for the separation of equimolar feed composition as it requires the least number of stages and provides energy saving comparable to that of the Petlyuk configuration.

As this simulation analysis is limited to equimolar feed composition, to determine the energy saving potential of various configurations for different feed compositions a similar approach can be followed. With decrease in intermediate component content, energy saving is expected to

\begin{tabular}{|c|c|c|c|c|}
\hline \multirow[b]{2}{*}{ Parameter } & \multicolumn{2}{|c|}{ Direct configuration } & \multicolumn{2}{|c|}{ Indirect configuration } \\
\hline & Column 1 & Column 2 & Column 1 & Column 2 \\
\hline Distillate rate $(\mathrm{kmol} / \mathrm{h})$ & 32.8 & 32.77 & 65.73 & 32.96 \\
\hline Molar boilup ratio & 1.61 & 3.8 & 4.7 & 1.76 \\
\hline Bottoms rate $(\mathrm{kmol} / \mathrm{h})$ & 67.2 & 34.43 & 34.27 & 32.77 \\
\hline Molar reflux ratio & 2.61 & 3.22 & 1.55 & 3.01 \\
\hline Number of stages & 24 & 24 & 22 & 29 \\
\hline
\end{tabular}

Table 6. Optimized parameters of conventional sequences.

Table 7. Table of comparison.

\begin{tabular}{lccccc}
\hline Configuration & $\begin{array}{c}\text { Number of } \\
\text { trays } \\
(\mathrm{C} 1)\end{array}$ & $\begin{array}{c}\text { Number of } \\
\text { trays } \\
(\mathrm{C} 2)\end{array}$ & $\begin{array}{c}\text { Reboiler duty } \\
(\mathrm{kW})\end{array}$ & $\begin{array}{c}\text { Condenser duty } \\
(\mathrm{kW})\end{array}$ & $\begin{array}{c}\text { \% Energy saving w.r.t. indirect } \\
\text { configuration }\end{array}$ \\
\hline Petlyuk & 25 & 61 & 1380.8 & -1329.1 & 32.96 \\
Configuration 1 & 47 & 46 & 1338 & -1286.3 & 35.03 \\
Configuration 2 & 28 & 40 & 1415.3 & -1363.8 & 31.28 \\
Direct & 24 & 24 & 2266.2 & -2214.6 & - \\
Indirect & 22 & 29 & 2059.5 & -2007.9 & - \\
\hline
\end{tabular}


reduce as remixing effect will reduce with decrease in intermediate component flow.

\section{Acknowledgements}

Authors are thankful to Council for Scientific and Industrial Research (CSIR) for supporting the present work.

\section{References}

[1] Hernandez S, Segovia-Hernandez J G and Rico-Ramirez V 2006 Thermodynamically equivalent distillation schemes to the Petlyuk column for ternary mixtures. Energy 32: 2176-2183

[2] Premkumar R and Rangaiah G P 2009 Retrofitting conventional column systems to dividing-wall columns. Chem. Eng. Res. Des. 87: 47-60

[3] Wright R O 1949 Fractionation apparatus, US Patent No. 2471134
[4] Petlyuk F B, Platonov V M and Slavinskii D M 1965 Thermodynamically optimal method of separating multicomponent mixtures. Int. J. Chem. Eng. 5(3): 555-561

[5] Fidkowski Z and Krolikowski L 1987 Minimum energy requirements for thermally coupled distillation systems. AIChE J. 33(4): 643-653

[6] Amminudin K A, Smith R, Thong D Y C and Towler G P 2001 Design and optimization of fully thermally coupled distillation columns. Part 1: preliminary design and optimization methodology. Trans. IChemE Part A 79: 701-715

[7] Yildirim Ö, Kiss A A and Kenig E Y 2011 Dividing wall columns in chemical process industry: a review on current activities. Sep. Purif. Technol. 80: 403-417

[8] Agrawal R and Fidkowski Z T 1998 More operable arrangements of fully thermally coupled distillation column. AIChE J. 44(11): 2565-2568

[9] Fidkowski Z and Krolikowski L 1986 Thermally coupled systems of distillation columns: optimization procedure. AIChE J. 32(4): 537-546 